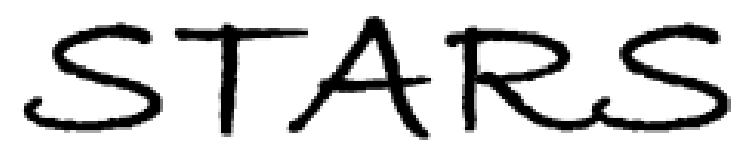

University of Central Florida

STARS

$1-1-2013$

\title{
Aqueous route for the synthesis of platinum, ruthenium and ceria nanoparticles on multi-walled carbon nanotubes for the electrooxidation of methanol and ethanol
}

\author{
Jordan M. Anderson \\ University of Central Florida \\ Matthew D. Mclnnis \\ University of Central Florida \\ Astha Malhotra \\ University of Central Florida \\ Lei Zhai \\ University of Central Florida
}

Find similar works at: https://stars.library.ucf.edu/facultybib2010

University of Central Florida Libraries http://library.ucf.edu

This Article is brought to you for free and open access by the Faculty Bibliography at STARS. It has been accepted for inclusion in Faculty Bibliography 2010 s by an authorized administrator of STARS. For more information, please contactSTARS@ucf.edu.

\section{Recommended Citation}

Anderson, Jordan M.; McInnis, Matthew D.; Malhotra, Astha; and Zhai, Lei, "Aqueous route for the synthesis of platinum, ruthenium and ceria nanoparticles on multi-walled carbon nanotubes for the electrooxidation of methanol and ethanol" (2013). Faculty Bibliography 2010 s. 3617.

https://stars.library.ucf.edu/facultybib2010/3617

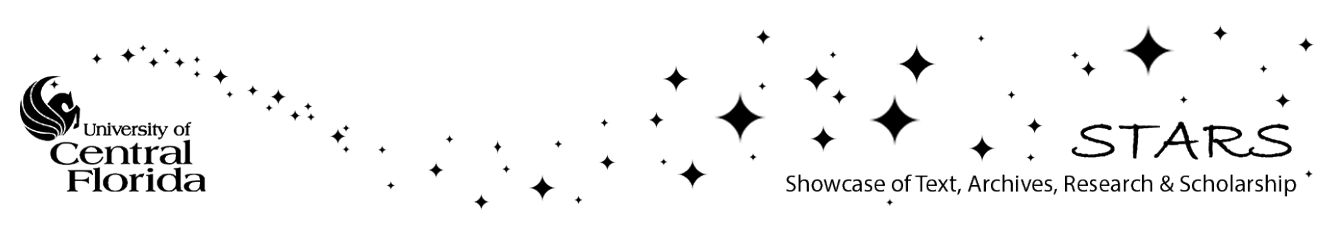




\title{
Materials Express
}

\section{Aqueous route for the synthesis of platinum, ruthenium and ceria nanoparticles on multi-walled carbon nanotubes for the electrooxidation of methanol and ethanol}

\author{
Jordan M. Anderson, Matthew D. McInnis, Astha Malhotra, and Lei Zhai* \\ Nanoscience Technology Center and Department of Chemistry, University of Central Florida, \\ 4000 Central Florida Blvd., Orlando, Florida 32816, USA
}

\begin{abstract}
The electrochemical oxidation of methanol and ethanol in acidic media was studied using electrodes composed of multi-walled carbon nanotubes (MWCNTs) decorated with Pt, Ru and ceria nanoparticles. Polystyrene sulfonate (PSS) was used to disperse the MWCNTs in water and provide nucleation sites for the growth of catalyst nanoparticles. Composite electrodes were characterized for structural and electrochemical properties and all electrodes modified with Ru displayed greater catalytic ability for alcohol oxidation than those without Ru. In addition, the inclusion of ceria seemed to increase the catalytic ability in every sample suggesting a synergistic effect between $\mathrm{Pt}, \mathrm{Ru}$ and ceria for the oxidation of methanol and ethanol. The catalytic effect of Pt and $\mathrm{Ru}$ concentration was studied by holding Ru concentrations constant and increasing the concentration of Pt. The same concentration of ceria was used for all modified electrodes. The results of this study show that the electrode prepared from 3:1 Pt:Ru solutions with ceria showed the highest peak current density for methanol oxidation (at $0.6 \mathrm{~V}$ vs. $\mathrm{Ag} / \mathrm{AgCl} / \mathrm{Cl}^{-}$) which was nearly 20 times greater than that for an unmodified Pt electrode. Similar results were seen for ethanol oxidation on the same electrode which resulted in peak current densities greater than 20 times those for the unmodified Pt electrode at $0.8 \mathrm{~V}$ versus $\mathrm{Ag} / \mathrm{AgCl}^{-} \mathrm{Cl}^{-}$.
\end{abstract}

Keywords: Carbon Nanotube, Ceria, Platinum, Ruthenium, Fuel Cell, Electrooxidation, Alcohol.

\section{INTRODUCTION}

Polymer electrolyte membrane fuel cells (PEMFCs) have been hailed as promising novel, greener alternatives for power generation. PEMFCs were originally conceived to work with hydrogen as a fuel; however, challenges in the handling and storage of hydrogen have sparked interest in the use of alternative materials as fuels. Among these fuels, both methanol and ethanol have been studied in

${ }^{*}$ Author to whom correspondence should be addressed. Email: lzhai@ucf.edu direct alcohol fuel cells (DAFCs). ${ }^{(1-7)}$ Methanol presents as a good choice due to its high energy density (compared to hydrogen) low operating temperatures, relatively quick start-up time and rapid response to load changes. Ethanol possesses all the benefits of methanol while also being inexpensive, non-toxic, and "green" since it can be produced from biomass. The best performing anode material for the electrochemical oxidation of alcohols is carbon supported platinum; however, limitations of Pt as a catalyst include the following: high overall cost, slow dynamics of alcohol oxidation, corrosion of the carbon substrate, and poisoning of the electrode surface. Under 
certain conditions the anodic $\mathrm{Pt}-\mathrm{COH}_{\text {ads }}$ are transformed to $\mathrm{Pt}-\mathrm{CO}_{\mathrm{ads}}$ which are extremely difficult to oxidize and therefore "poison" the electrode surface. Many research groups have studied bimetallic catalysts in order to reduce concentration of Pt (to lower cost) and improve alcohol oxidation kinetics. ${ }^{(8-13)}$ One such catalyst that has been widely studied is $\mathrm{Pt} / \mathrm{Ru} .^{(14-16)} \mathrm{Pt} / \mathrm{Ru}$ catalysts have been widely studied to decrease $\mathrm{CO}$ poisoning by the introduction of $\mathrm{Ru}-\mathrm{OH}$ sites which promote the conversion of $\mathrm{Pt}-\mathrm{COH}_{\mathrm{ads}}$ to $\mathrm{CO}_{2}$ rather than $\mathrm{CO}$. The elimination of $\mathrm{Pt}-\mathrm{CO}_{\mathrm{ad}}$ frees Pt surface sites for methanol oxidation and allows for an increases in current. The catalytic oxidation of ethanol is more complicated than that of methanol due to the $\mathrm{C}-\mathrm{C}$ bond which results in reaction intermediates and products not seen in methanol oxidation. Ethanol oxidation on $\mathrm{Pt}$ is generally believed to follow two parallel reactions which result in the complete and incomplete oxidation. The complete oxidation yields $12 \mathrm{e}^{-}$while the incomplete oxidation produces $2 \mathrm{e}^{-}$(for acetaldehyde and ethane-1,1-diol) and $4 \mathrm{e}^{-}$(for acetic acid). It has been shown that little $\mathrm{CO}_{2}$ is produced in the oxidation of ethanol on Pt, leading researchers to believe that the primary mode of ethanol oxidation is through the incomplete oxidation mechanism. ${ }^{(17,18)}$ Addition of Ru and other transition metals have been shown to increase the catalytic ability of Pt catalysts toward the oxidation of ethanol which could be the result of $-\mathrm{OH}_{\mathrm{ad}}$ species promoting the formation of AA ( $4 \mathrm{e}^{-}$compared to $2 \mathrm{e}^{-}$for $\mathrm{AAL}$ and $\mathrm{ED}$ ); however, more studies need to be performed to understand the exact mechanism of bimetallic catalysts toward alcohol electrooxidation.

Metal oxides have also been widely studied in Pt-composite electrodes for fuel cells in order to increase catalytic activity. ${ }^{(13,19-21)}$ One metal oxide that has been generating attention is ceria $\left(\mathrm{CeO}_{2}\right) \cdot{ }^{(19,22-24)} \mathrm{CeO}_{2}$ has shown a great ability to store and release oxygen (oxygen carrying capacity) with little distortion of the lattice which is due to the cerium atom's ability to reversibly undergo the oxidation/reduction processes from $\mathrm{Ce}^{4+}$ to $\mathrm{Ce}^{3+} .{ }^{(25-29)}$ The oxidation of alcohols with Pt/ceria catalysts is generally believed to proceed similar to that of $\mathrm{Ru}$, with the production of $\mathrm{CeO}_{2}-\mathrm{OH}_{\text {ads }}$ species which decrease $\mathrm{CO}_{\mathrm{ads}}$ species on the surface of the Pt electrode; however the mechanism is not well understood. When ceria is presented in the nanoscale (nanoceria), the catalytic ability has shown to increase, most likely due to the high surface area which offers a large number of oxygen vacancies and enhanced mobility of these vacancies.

While research has shown that the $\mathrm{Pt} / \mathrm{Ru} /$ ceria composite electrodes have an increased catalytic ability for the oxidation of alcohols, the support material for these composites is also important. Due to their high electrical conductivity, chemical stability and surface area, multiwalled carbon nanotubes (MWCNTs) present as excellent candidates for metal nanoparticle supports in fuel cell catalysts. ${ }^{(30-32)}$ MWCNTs serve as a high surface area scaffold to both hold the metal nanoparticles and to transfer electrons from the oxidizing fuel. The size, size distribution, stability and morphology of metal nanoparticles are greatly affected by MWCNT/composite preparation method. ${ }^{(33-35)}$ These factors have all shown to affect the catalytic ability of composite materials; therefore in this study, it is our intention to show how the growth of $\mathrm{Pt} / \mathrm{Ru} /$ ceria composites on MWCNTs directly enhances methanol and ethanol oxidation.

The conventional impregnation method for metal loading involves the reduction of metal ions on the MWCNT surface in solution based techniques. Since the MWCNT surface is inherently inert, it is difficult to attach metal nanoparticles to the surface. Typical processes to induce nucleation sites on MWCNTs involve refluxing MWCNT in nitric acid. This process creates acidic sites on the MWCNT surface which promote the growth of metal nanoparticles; however, long reflux times and difficulties with using strong acids are major drawbacks to processing large quantities of modified MWCNTs. In this study, polystyrene sulfonic acid (PSS) was incorporated into the MWCNT/metal nanoparticle composites. The motivation for using PSS in this study is twofold. First, PSS acts as a dispersing agent for MWCNTs in aqueous solutions and the sulfonic acid groups provide nucleation sites for metal nanoparticle growth. Second, the sulfonic acid groups may facilitate a stronger interaction between the composite electrode and the Nafion ${ }^{\circledR}$ membrane commonly used as the solid state electrolyte in PEMFCs. While this study focused on the catalytic ability of composite electrodes, in subsequent studies we hope to monitor the effect of PSS on the electrode/membrane interface in a fuel cell. Based on results seen for $\mathrm{Pt} / \mathrm{Ru}$ and $\mathrm{Pt} /$ ceria composites and the enhanced surface area and conductivity provided by MWCNTs; our group has designed $\mathrm{Pt} / \mathrm{Ru} /$ ceria composites supported on MWCNTs and tested these composites for the catalytic oxidation of methanol and ethanol.

\section{EXPERIMENTAL DETAILS}

\subsection{Materials}

All aqueous solutions were prepared from triply distilled water with $18 \mathrm{M} \Omega / \mathrm{cm}$ resistivity (Barnstead B-Pure). Reagent grade methanol (Aldrich) and ethanol (Aldrich) were used to prepare $1 \mathrm{M}$ solutions. $0.5 \mathrm{M} \mathrm{H}_{2} \mathrm{SO}_{4}$ was used as support electrolyte for alcohol solutions. High purity potassium hexachloroplatinate $\left(\mathrm{K}_{2} \mathrm{PtCl}_{6}\right)$ (Aldrich) and ruthenium chloride $\left(\mathrm{RuCl}_{3}\right)$ (Aldrich) were used to synthesize Pt and Ru nanoparticles on the surface of MWCNTs. Cerium nitrate $\left(\mathrm{Ce}\left(\mathrm{NO}_{3}\right)_{3}\right)$ (Aldrich) were used to prepare MWCNT/ceria composites. Potassium hydroxide (Acros) and hydrazine hexahydrate (Acros) were used as oxidizing and reducing agents respectively. High molecular 
weight polystyrene sulfonic acid (PSS) (Aldrich) was used as a dispersing agent for multiwalled carbon nanotubes in aqueous solutions. All chemicals were used as received unless otherwise specified.

\subsection{Electrochemical Apparatus}

In this work a three-electrode apparatus was used for all electrochemical procedures. Working electrodes consisted of glassy carbon $2 \mathrm{~mm}$ diameter electrodes with a saturated $\mathrm{Ag} / \mathrm{AgCl} / \mathrm{Cl}^{-}(\mathrm{Ag} / \mathrm{AgCl})$ electrode used as the reference electrode, and a platinum wire used as a counter electrode. Composite material was spray coated onto the surface of glassy carbon electrodes prior to electrochemical characterization. An unmodified polished polycrystalline Pt working electrode ( $2 \mathrm{~mm}$ diameter) was used as a basis for comparing alcohol oxidation ability. All electrodes were obtained from $\mathrm{CH}$ Instruments, Inc. A $\mathrm{CH}$ Instruments 660D potentiostat was used to obtain all electrochemical measurements.

\subsection{Composite Material Synthesis}

The synthesis of composite material proceeded through completely aqueous routes. MWCNTs were obtained from Nanolab (Newton, MA). MWCNT were dispersed in water using polystyrene sulfonate (PSS) in an equal mass concentration. As the dispersion was sonicated, PSS stabilized the nanotubes in water through charge repulsion. The negatively charged PSS layer attracted metal ions and serve as a template for subsequent nano-structure formation. Interaction of growing nuclei with the large number of surface sites $\left(-\mathrm{SO}_{3}^{-}\right)$facilitated the material to grow in nanodimensions and retard interparticle agglomeration. Once the MWCNTs were dispersed, $\mathrm{Ce}\left(\mathrm{NO}_{3}\right)_{3}$ was added to the dispersion. Ceria nanoparticles wereformed by the oxidation of $\mathrm{Ce}^{3+}$ ions onto the surface of MWCNTs through the drop-wise addition of $\mathrm{KOH}$. Various concentrations of $\mathrm{Ce}\left(\mathrm{NO}_{3}\right)_{3}$ were added to solutions of dispersed MWCNTs. It was found that concentrations below $0.01 \mathrm{M}$ resulted in well dispersed ceria/MWCNT suspensions. At concentrations above $0.01 \mathrm{M}$, the ceria/MWCNTs composited formed large un-dispersible agglomerates. The concentration of $\mathrm{Ce}\left(\mathrm{NO}_{3}\right)_{3}$ was therefore kept constant at $0.01 \mathrm{M}$ throughout the study in order to provide the most well dispersed MWCNTs with the highest concentration of ceria nanoparticles. $\mathrm{Pt} / \mathrm{Ru}$ nanoparticles were formed by adding $\mathrm{Pt}$ and $\mathrm{Ru}$ ions $\left(\mathrm{H}_{2} \mathrm{PtCl}_{6}\right.$ and $\left.\mathrm{RuCl}_{3}\right)$ to the dispersion and reducing the ions onto the MWCNT surface through the addition of $\mathrm{NaBH}_{4}$. Figure 1 shows a basic representation of the synthesis of MWCNT/Ceria/Pt/Ru composites from oxidation of $\mathrm{Ce}^{4+}$ and subsequent reduction of $\mathrm{Pt}^{4+}$ and $\mathrm{Ru}^{3+}$. Composites of various $\mathrm{Pt} / \mathrm{Ru}$ concentration were synthesized by holding the concentration of $\mathrm{Ru}$ constant while increasing the concentration of $\mathrm{Pt}$ in the following Pt:Ru ratios: 3:1, 2:1, 1:1 and one sample with only Pt. The PRCe 3:1, PRCe 2:1, PRCe 1:1, PCe, PNCe and UP electrodes (see Table I) were fabricated by combining the MWCNT/Pt/Ru/ceria composites with Nafion ${ }^{\circledR}$ and spray coating the aqueous dispersions onto glassy carbon working electrodes. Glassy carbon electrodes were chosen due to their inert behavior toward alcohol oxidation. All catalytic ability of the modified electrodes can therefore be traced to the MWCNT/metal composites and not the underlying electrode substrate. A total of $1 \mathrm{mg}$ of composite material was used to coat working electrode surfaces for every electrode studied. Assuming complete reduction of the metal ions during synthesis the theoretical $\mathrm{Pt} / \mathrm{Ru}$ loading was calculated to be $100 \mu \mathrm{g} / \mathrm{cm}^{2}$, which is $10 \%$ of the composite. In a similar fashion, the theoretical ceria loading on all composite electrodes was calculated to be around $25 \mu \mathrm{g} / \mathrm{cm}^{2}$ or $2.5 \%$ of the total composite.

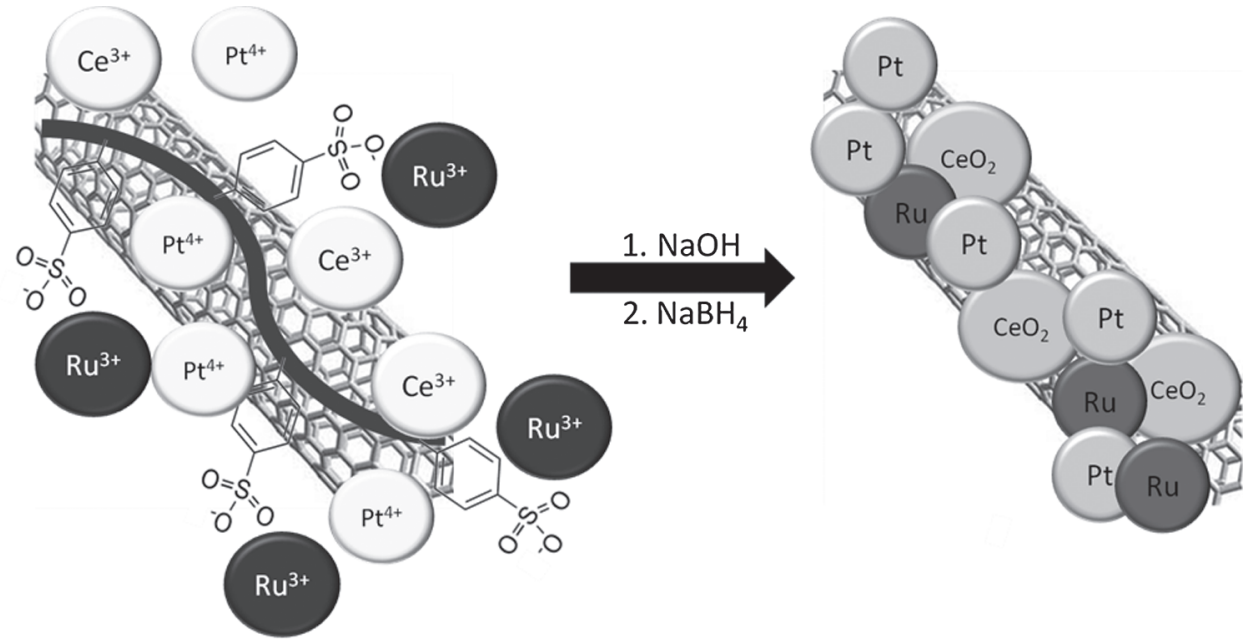

Fig. 1. Synthesis of Ceria and Pt/Ru nanoparticles on MWCNTs by subsequent oxidation and reduction reactions. 
Table I. Pt surface areas estimated from EDX and Cu-UPD data.

\begin{tabular}{lcccc}
\hline Electrode composition & Abbreviated name & Pt:Ru from EDX & Total surface area & Pt surface area \\
\hline MWCNT/Ceria Pt:Ru 3:1 & PRCe 3:1 & $5.8: 1$ & $1.42 \mathrm{~cm}^{2}$ & $1.21 \mathrm{~cm}^{2}$ \\
MWCNT/Ceria Pt:Ru 2:1 & PRCe 2:1 & $2: 1$ & $0.93 \mathrm{~cm}^{2}$ & $0.72 \mathrm{~cm}^{2}$ \\
MWCNT/Ceria Pt:Ru 1:1 & PRCe 1:1 & $1.5: 1$ & $2.40 \mathrm{~cm}^{2}$ & $0.62 \mathrm{~cm}^{2}$ \\
MWCNT/Ceria/Pt & PCe & - & $0.91 \mathrm{~cm}^{2}$ & $2.40 \mathrm{~cm}^{2}$ \\
MWCNT/Pt & PNCe & - & $0.07 \mathrm{~cm}^{2}$ & $0.91 \mathrm{~cm}^{2}$ \\
Unmodified Pt & UP & - & $0.07 \mathrm{~cm}^{2}$ \\
\hline
\end{tabular}

\section{RESULTS AND DISCUSSION}

\subsection{Characterization}

The composite material was investigated using X-ray photoelectron spectroscopy (Physical Electronics 5400 ESCA XPS) to identify the composition of composite material. The wide survey XPS spectrum of the PRCe 3:1 composite is shown in Figure 2, which displays pronounced $\mathrm{Pt} 4 \mathrm{f} 7$, $\mathrm{Ce} 4 \mathrm{~d}+3 \mathrm{~d} 5$ and $\mathrm{O}$ 1s peaks in addition to the overlapped $\mathrm{C} 1 \mathrm{~s}$ and $\mathrm{Ru} 3 \mathrm{~d}$ region. The $\mathrm{C} 1 \mathrm{~s}$ signal originates from the MWCNT background. The $\mathrm{N} 1 \mathrm{~s}$ peak provides the possibility that unreacted $\mathrm{Ce}\left(\mathrm{NO}_{3}\right)_{3}$ was present in the composite. The $\mathrm{S} 2 \mathrm{p} 3$ peak is characteristic of the $\mathrm{SO}_{3}^{-}$functional groups in PSS. It appears that $\mathrm{Pt}, \mathrm{Ru}$ and ceria ions were successfully deposited onto the MWCNT/PSS surface through subsequent reduction and oxidation reactions. Comparable results are shown in similar studies. ${ }^{(36,37)}$

The surface structure of metal nanoparticles grown on MWCNTs was explained by TEM. Figure 3 shows images of the MWCNTs coated with ceria $(\mathrm{a}, \mathrm{d}), \mathrm{Pt} / \mathrm{Ru}(\mathrm{b}, \mathrm{e})$ and $\mathrm{Pt} / \mathrm{Ru} /$ ceria ( $\mathrm{Pt}: \mathrm{Ru}$ 3:1 ratio) (c, f). The nanoparticles show a good distribution on the MWCNTs. The TEM study showed that all MWCNT were coated similarly with metal nanoparticles indicating good uniformity within samples. Ceria nanoparticles can easily be seen on the surface of

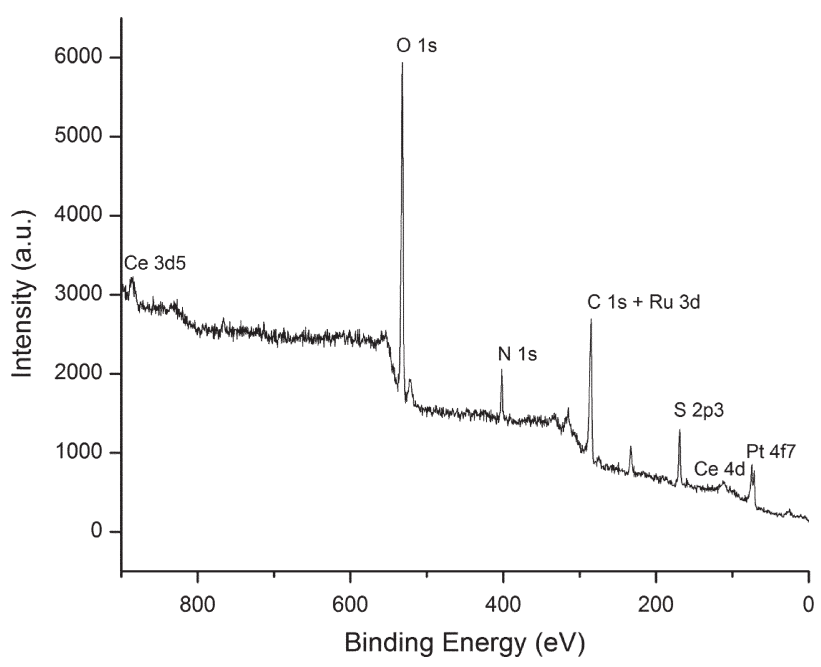

Fig. 2. Wide survey XPS spectra of the PRCe 3:1 composite.
MWCNTs in Figure 3(d). Size and shape of the nanoparticles varies. On average it seems ceria nanoparticles have dimensions between 5-10 nm. Pt/Ru nanoparticles can be seen with much more uniform spherical dimensions in Figure 3(e). The size of these particles is between 4-5 $\mathrm{nm}$ and they are evenly attached to the surface of the MWCNT. Pt/Ru and ceria nanoparticles on MWCNTs are shown in Figure 3(f). The irregularly shaped ceria particles can be seen alongside the smaller, more uniform $\mathrm{Pt} / \mathrm{Ru}$ particles. The image displays the possibility that $\mathrm{Pt} / \mathrm{Ru}$ nanoparticles grow on the surface of ceria nanoparticles during the subsequent oxidation and reduction reactions. The images provide evidence that high metal nanoparticle surface area can be achieved by using MWCNTs as support material.

To gain a better understanding of nanoparticles grown on MWCNTs, High resolution TEM (HRTEM) was performed in tandem with EDX. HRTEM and EDX experiments were performed using a FEI Tecnai F30 TEM equipped with an energy dispersive $\mathrm{X}$-ray detector. Figure 4 shows the HRTEM of $\mathrm{Pt} / \mathrm{Ru} /$ ceria ( $\mathrm{Pt}: \mathrm{Ru}$ 3:1 ratio) composite on a MWCNT. The inside diameter of MWCNTs appears to be $\sim 5 \mathrm{~nm}$ and the outside diameter is close to $20 \mathrm{~nm}$. The layers of the MWCNT can also be distinguished and show to be $\sim 0.3 \mathrm{~nm}$ apart. As can be seen metal nanoparticles have dimensions of 4-5 nm. The distance between nanopartles varies, but stays within 1-5 nm. The proximity of metal/metal oxide nanoparticles to one another has shown to impact the mechanism of alcohol oxidation. Close nanoparticle proximity is preferred in order to allow the reaction of adsorbed $(-\mathrm{OH})$ species on ceria and $\mathrm{Ru}$ with the $\mathrm{CO}$ adsorbed on Pt sites.

Figure 5 shows the dark field image of $\mathrm{Pt} / \mathrm{Ru} /$ ceria nanoparticles grown on MWCNTs along with the EDX spectrum. The dark field TEM image shows the higher density metal/metal oxide nanoparticles well dispersed along the surface of the MWCNT. EDX results confirm the identity of $\mathrm{Pt}, \mathrm{Ru}$ and ceria nanoparticles. The $\mathrm{C}$ peak is the result of the MWCNT surface and the $\mathrm{Cu}$ peak is from the TEM grid used to mount the composite sample. Concentrations of $\mathrm{Pt}, \mathrm{Ru}$ and ceria were estimated from EDX data. EDX estimates show that the Pt and Ru content of the $\mathrm{Pt}: \mathrm{Ru} 3: 1$ composite material was $6.4 \%$ and $1.1 \%$ respectively (7.5\% $\mathrm{Pt} / \mathrm{Ru})$. In addition the $\mathrm{Pt}: \mathrm{Ru} 2: 1$ composite was found to have $5.2 \%$ and $2.6 \% \mathrm{Pt}$ to $\mathrm{Ru}$ concentration $(7.8 \% \mathrm{Pt} / \mathrm{Ru})$, and the atomic concentration of the 


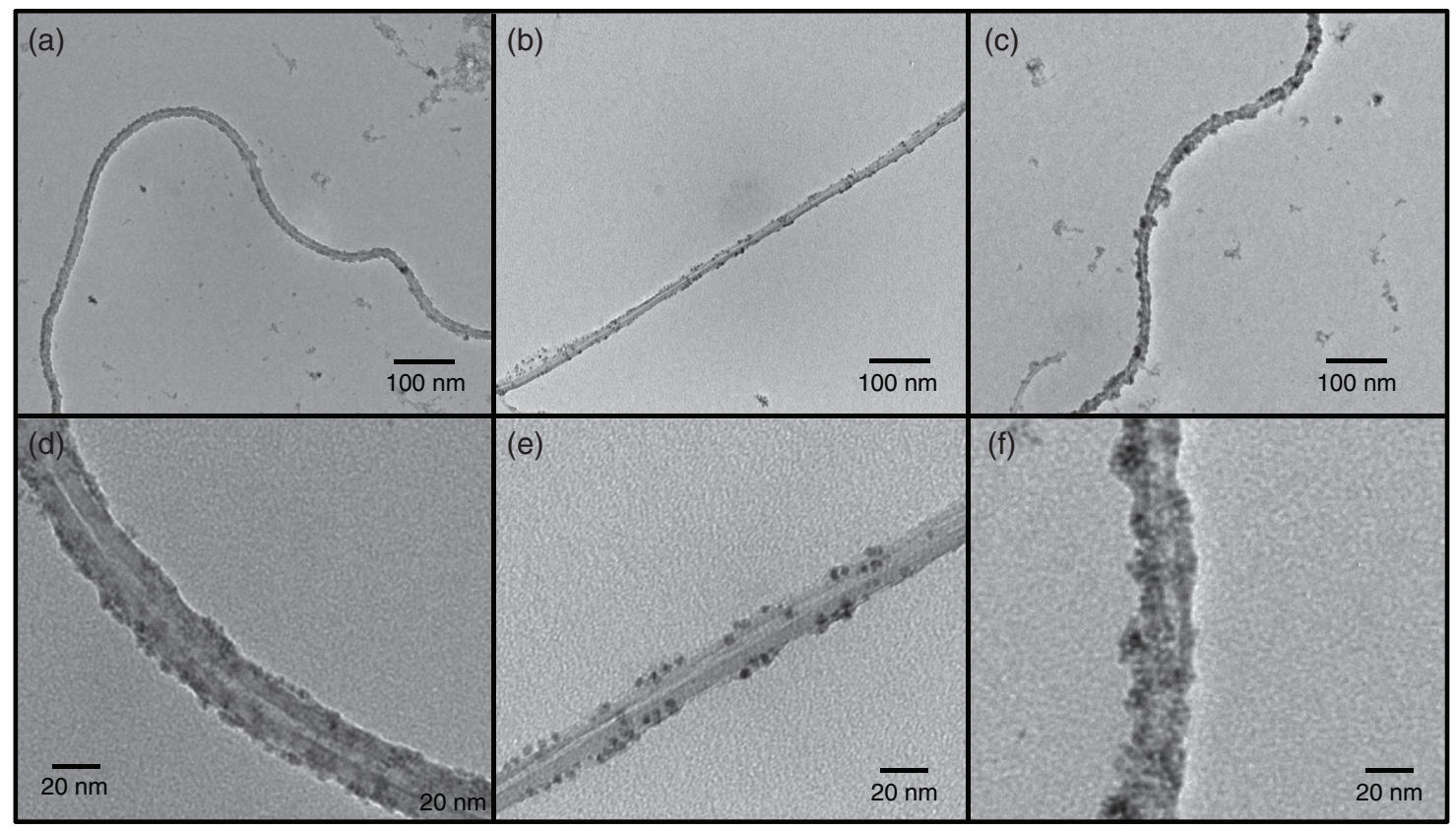

Fig. 3. TEM images showing composites of (a, d) MWCNT/Ceria, (b, e) MWCNT/Pt/Ru, and (c, f) PRCe 3:1.

$\mathrm{Pt}: \mathrm{Ru} 1: 1$ electrode was found to be $4.4 \%$ and $2.9 \% \mathrm{Pt}$ to $\mathrm{Ru}$ respectively $(7.3 \% \mathrm{Pt} / \mathrm{Ru})$. The $\mathrm{Pt} / \mathrm{Ru}$ loading estimated from EDX is in good agreement with the theoretical concentration calculated from metal ions in solution. A comparison of the theoretical and EDX estimated concentrations suggests that the fabrication procedures lead to the reduction of most metal ions. The $\mathrm{Pt} / \mathrm{Ru}$ metal loading on the composite catalysts can also be assumed to be near $100 \mu \mathrm{g} / \mathrm{cm}^{2}$ as predicted by the theoretical loading.

Table I provides the theoretical as well as EDX estimated percent loading for all $\mathrm{Pt} / \mathrm{Ru}$ modified electrodes. The EDX estimates show that the concentration of ceria was $\sim 2 \%$ in each sample suggesting good reproducibility in $\mathrm{Ce}\left(\mathrm{NO}_{3}\right)_{3}$ oxidation procedures.

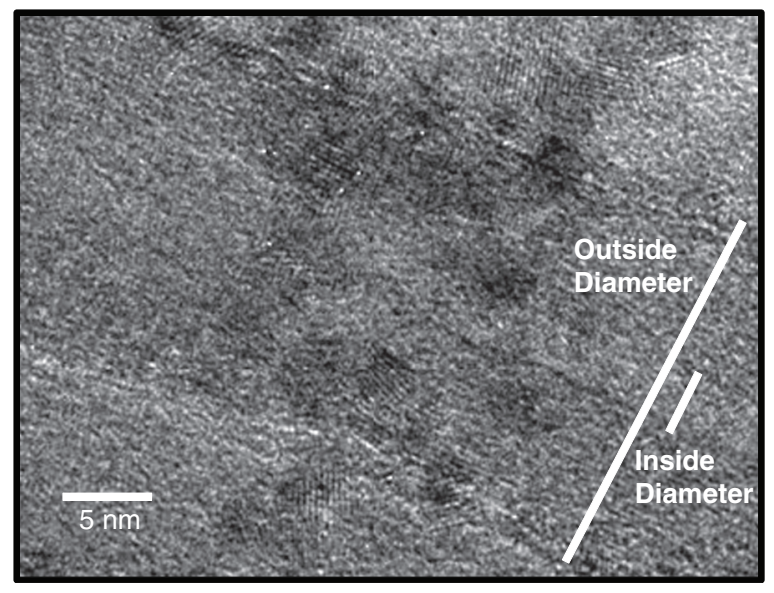

Fig. 4. HRTEM image of the PRCe 3:1 composite showing metal nanoparticles supported on a MWCNT. Outside and inside diameter of the MWCNT are indicated.
The estimated concentration is in good agreement with the $2.5 \%$ concentration predicted by the theoretical ceria load and it can be assumed that each electrode was composed of $25 \mu \mathrm{g} / \mathrm{cm}^{2}$ of ceria.

The ratio of Pt:Ru was also calculated from the EDX estimates of $\mathrm{Pt}$ and $\mathrm{Ru}$ concentration and the ratios are given in Table I. For the PRCe 3:1 and the PRCe 1:1 electrodes there appears to be a discrepancy between ratio of metal ions in solution and metal nanoparticle concentration estimated from EDX on MWCNT surfaces. The difference in atomic ratio between the solution and resulting composite material is most likely due to the relative attraction of $\mathrm{Pt}$ and $\mathrm{Ru}$ either to the PSS anionic functional groups, the ceria surface, or both. Because of the complexity of the adsorbing surface and the added complication of the reduction step of the $\mathrm{Pt}$ and $\mathrm{Ru}$, further studies are necessary to provide a clear mechanistic explanation of this trend.

\subsection{Surface Area Determination}

In order to make composite electrodes for alcohol oxidation, MWCNT composite material was combined with $\mathrm{Nafion}^{\circledR}$ in aqueous suspensions and spray coated with an airbrush onto glassy carbon electrodes (CH Instruments). An unmodified Pt electrode was used to compare the catalytic activity of composite electrodes. The shape of CVs in $0.5 \mathrm{M} \mathrm{H}_{2} \mathrm{SO}_{4}$ for MWCNT/Pt composite electrodes was used to determine $\mathrm{Pt}$ characteristics. Figure 6. provides the CVs of the MWCNT/Ceria/Pt composite electrode (solid curve) alongside that of an unmodified Pt electrode (dotted curve). The cyclic voltammogram is presented with the ordinate in milliamps. The CV of 

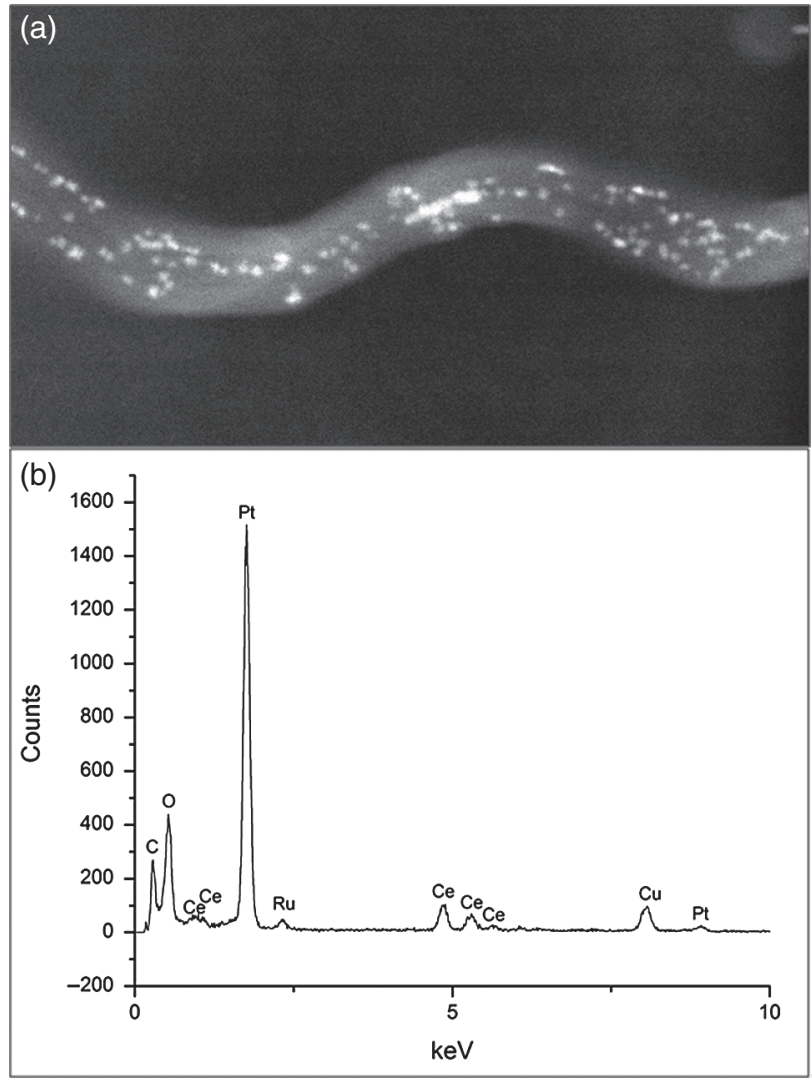

Fig. 5. (a) Dark field TEM image of the PRCe 3:1 composite showing region scanned for EDX and (b) EDX spectrum of PRCe 3:1.

the composite shows the characteristic hydrogen region $(-0.15$ to $0.1 \mathrm{~V})$ which indicates Pt in on the surface of the electrode. It can be seen that the MWCNT/Ceria/Pt electrode has a much higher specific current in the hydrogen

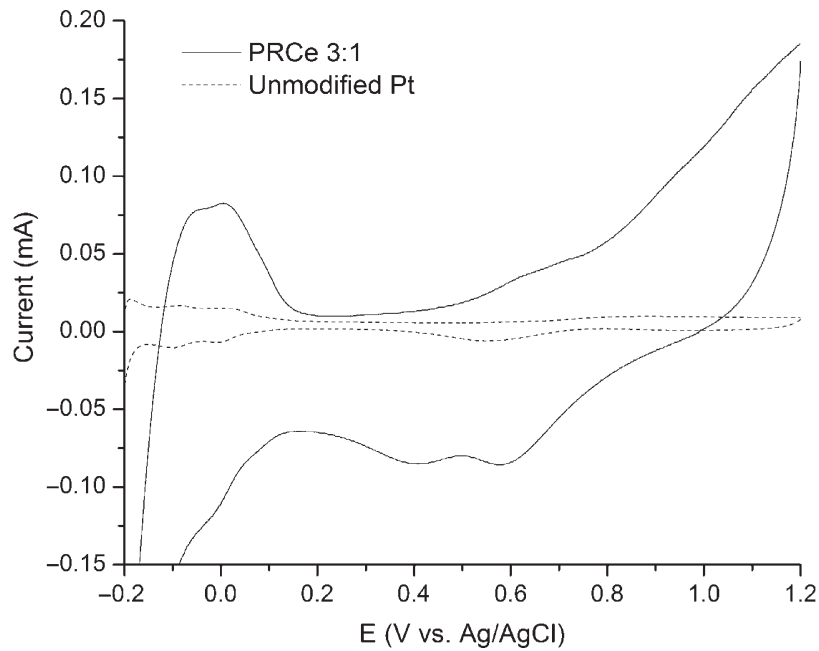

Fig. 6. Cyclic voltammetry of MWCNT/Ceria/Pt modified electrode (solid curve) and unmodified Pt electrode (dotted curve) in a $0.5 \mathrm{M}$ $\mathrm{H}_{2} \mathrm{SO}_{4}$ electrolyte solution. The hydrogen adsorption region for each electrode can clearly be seen in the potential region of -0.15 to $0.1 \mathrm{~V}$ versus an $\mathrm{Ag} / \mathrm{AgCl}$ reference electrode. region which indicates higher surface area in MWCNT/Pt composite samples. The hydrogen adsorption region is well known to provide information about the active $\mathrm{Pt}$ surface area in composite electrodes; however, the overlap of hydrogen and Ru oxidation currents makes the potential window from -0.15 to $1.00 \mathrm{~V}$ difficult to interpret in samples containing both $\mathrm{Pt}$ and $\mathrm{Ru} .{ }^{(38,39)}$ In order to better understand the total surface area of $\mathrm{Pt} / \mathrm{Ru}$ composites a variety of electrochemical techniques are in use..$^{(40,41)}$ Copper underpotential deposition (Cu-UPD) is one method that has shown good results for $\mathrm{Pt} / \mathrm{Ru}$ composite surface area determination. ${ }^{(41)}$ Copper is an ideal metal for UPD on both $\mathrm{Pt}$ and $\mathrm{Ru}$ because of the similarity of the atomic radii of the three metals.

In this study the total surface area was determined for all $\mathrm{Pt} / \mathrm{Ru}$ composite electrodes by calculating the charge transfer from $\mathrm{Cu}$ monolayer oxidation in $\mathrm{CuSO}_{4}$ solution according to published procedures. ${ }^{(1)}$ Figure 7 shows the $\mathrm{Cu}$ stripping region in $\mathrm{CV}$ of the MWCNT/Ceria/Pt composite electrode between 0 to $0.5 \mathrm{~V}$ in the anodic scan. The specific charge transfer $\left(\mathrm{Q}_{H}\right)$ can be obtained from integrating the $\mathrm{Cu}$ stripping region while assuming an adsorption ratio of a single $\mathrm{Cu}$ atom to each surface metal atom and an electrosorption valency of +2 . The average charge value associated with $\mathrm{Cu}$ monolayer formation is $420 \mu \mathrm{C}$ $\mathrm{cm}^{-2}$. Therefore the total surface area is calculated from the following:

$$
\mathrm{SA}=\left(\mathrm{Q}_{\mathrm{H}}\right) /\left(420 \mu \mathrm{C} \mathrm{cm}^{-2}\right)
$$

Calculations of surface area for all electrodes were carried out by integrating the current voltage curve, correcting for background current and using the conversion factor of $420 \mu \mathrm{C} \mathrm{cm}^{-2}$. Since Pt is known to provide the catalytic ability for alcohol oxidation, it is useful to calculate the active Pt surface area. In this study we used

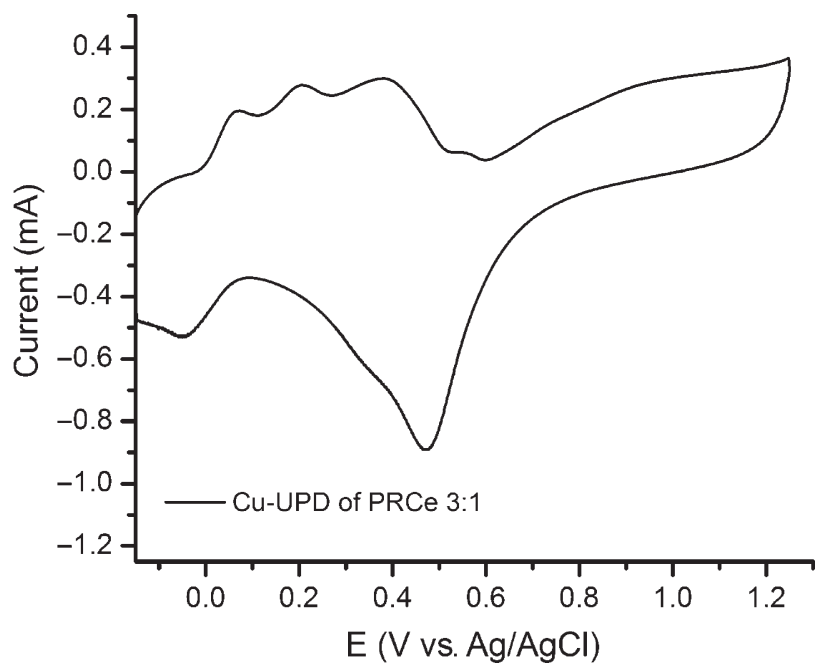

Fig. 7. Cyclic voltammetry showing the stripping of $\mathrm{Cu}$ monolayer deposited during underpotential deposition. 
the estimated ratios of $\mathrm{Pt}: \mathrm{Ru}$ from EDX data combined with the total surface area from $\mathrm{Cu}$-UPD measurements to calculate the active Pt surface area. Table I provides the EDX estimates, total surface area and Pt surface area for each electrode. All composite electrodes have at least one order of magnitude greater surface area than the unmodified Pt electrode. The data indicates that total surface area is dependent on $\mathrm{Pt}, \mathrm{Ru}$ and ceria content. The total surface areas demonstrate that the addition of ceria acts to increase the metal surface area. This may be the result of $\mathrm{Pt} / \mathrm{Ru}$ nanoparticle formation on previously deposited ceria on the MWCNT surface. The rough MWCNT/ceria surface could act as nucleation sites for the formation of $\mathrm{Pt}$ and $\mathrm{Ru}$ nanoparticles. The highest total surface area is given by the PCe electrode and the total surface area dramatically decreases with the addition of Ru. It seems clear that Pt has a lower affinity for adsorption to the PSS surface of MWCNTs than that of ceria-coated PSS, but an understanding of the forces driving this trend would require further study. While $\mathrm{Ru}$ is well known to increase the catalytic ability of Pt electrodes towards the oxidation of alcohols, it seems that an increase in $\mathrm{Ru}^{3+}$ ions during synthesis causes a decrease in total surface area. All synthesis solutions were prepared with a total of $2 \mathrm{mM}$ concentration of $\mathrm{Pt}^{4+}$ and $\mathrm{Ru}^{3+}$ ions and it is assumed that similar molar concentrations were achieved for each composite. The decrease in total surface area at higher $\mathrm{Ru}$ concentrations may be the result of larger nanoparticle formation. The total surface area would then be adversely affected by higher $\mathrm{Ru}^{3+}$ and lower $\mathrm{Pt}^{4+}$ ion concentrations during nanoparticle synthesis. It is therefore important to determine the $\mathrm{Pt}^{4+}$ and $\mathrm{Ru}^{3+}$ ionic concentrations that result in composite material with both high surface area and catalytic ability.

The Pt surface area is an important aspect of the electrode fabrication. From the total surface area and the $\mathrm{Pt}: \mathrm{Ru}$ ratios estimated from EDX, the Pt surface area was calculated and is given in Table I. The PCe electrode has the highest Pt surface area followed by the PRCe 3:1 electrode. This is expected since these two composites were synthesized in solutions containing the highest concentration of Pt ions. After determination of Pt surface area, the electrodes were used for the oxidation of alcohols and the current density (j) of methanol and ethanol oxidation with respect to the Pt surface area was calculated (see Table II).

\subsection{Electrooxidation of Methanol}

The electrocatalytic activity of the MWCNT composite electrodes for the oxidation of methanol was characterized by $\mathrm{CV}$ in $1 \mathrm{M}$ methanol solutions with $0.5 \mathrm{M} \mathrm{H}_{2} \mathrm{SO}_{4}$ as support electrolyte. Prior to $\mathrm{CV}$, all methanol solutions were bubbled with $\mathrm{N}_{2}$ for 15 minutes to remove all $\mathrm{O}_{2}$ dissolved in solution. The current density was determined for each electrode by dividing the current by the
Table II. Summary of electrochemical data from the oxidation of methanol and ethanol on composite electrodes.

\begin{tabular}{lcccc}
\hline Electrode & $i_{\mathrm{pa}}($ Methanol $)$ & $j_{\mathrm{pa}}($ Methanol $)$ & $i_{\mathrm{pa}}($ Ethanol $)$ & $j_{\mathrm{pa}}($ Ethanol $)$ \\
\hline PRCe 3:1 & $9.5 \mathrm{~mA}$ & $7.9 \mathrm{~mA} / \mathrm{cm}^{2}$ & $7.9 \mathrm{~mA}$ & $6.5 \mathrm{~mA} / \mathrm{cm}^{2}$ \\
PRCe 2:1 & $2.9 \mathrm{~mA}$ & $4.6 \mathrm{~mA} / \mathrm{cm}^{2}$ & $3.6 \mathrm{~mA}$ & $5.6 \mathrm{~mA} / \mathrm{cm}^{2}$ \\
PRCe 1:1 & $1.6 \mathrm{~mA}$ & $3.7 \mathrm{~mA} / \mathrm{cm}^{2}$ & $2.1 \mathrm{~mA}$ & $4.8 \mathrm{~mA} / \mathrm{cm}^{2}$ \\
PCe & $6.2 \mathrm{~mA}$ & $2.6 \mathrm{~mA} / \mathrm{cm}^{2}$ & $3.4 \mathrm{~mA}$ & $1.4 \mathrm{~mA} / \mathrm{cm}^{2}$ \\
PNCe & $1.2 \mathrm{~mA}$ & $1.3 \mathrm{~mA} / \mathrm{cm}^{2}$ & $0.4 \mathrm{~mA}$ & $0.5 \mathrm{~mA} / \mathrm{cm}^{2}$ \\
UP & $0.03 \mathrm{~mA}$ & $0.4 \mathrm{~mA} / \mathrm{cm}^{2}$ & $0.02 \mathrm{~mA}$ & $0.3 \mathrm{~mA} / \mathrm{cm}^{2}$ \\
\hline
\end{tabular}

calculated Pt surface area. Figure 8 shows the overlaid plots of composite electrodes towards the electrooxidation of methanol. The ordinate is presented in current density $\left(\mathrm{mA} / \mathrm{cm}^{2}\right)$. The potential was swept between -0.15 and $1.2 \mathrm{~V}$ versus an $\mathrm{Ag} / \mathrm{AgCl}$ reference electrode. The catalytic ability of composite electrodes is typically assessed by monitoring peak current density in the anodic scan $\left(j_{\mathrm{pa}}\right)$ of CVs. Table II provides the $j_{\mathrm{pa}}$ for each electrode at $0.6 \mathrm{~V}$ versus $\mathrm{Ag} / \mathrm{AgCl}$. As expected the $j_{\mathrm{pa}}$ of all composite electrodes were higher than that for the unmodified $\mathrm{Pt}$ electrode indicating that MWCNT/Pt composites have significantly greater catalytic ability than unmodified Pt for the oxidation of methanol. Each $j_{\mathrm{pa}}$ for modified electrodes was divided by the $j_{\mathrm{pa}}$ for the unmodified Pt electrode to help determine the increase in catalytic ability. The PRCe 3:1 electrode shows nearly 20 times greater catalytic ability than the unmodified Pt electrode. Although surface area calculations show that $\mathrm{Pt}: \mathrm{Ru}$ composites with higher $\mathrm{Ru}$ concentration have lower Pt surface areas, Figure 8 shows that all composites with $\mathrm{Ru}$ show higher $j_{\mathrm{pa}}$ than those without without $\mathrm{Ru}$. The PRCe 3:1 has the highest $j_{\mathrm{pa}}$ for the oxidation of methanol followed by PRCe 2:1 and PRCe 1:1. This indicates that the catalytic enhancement

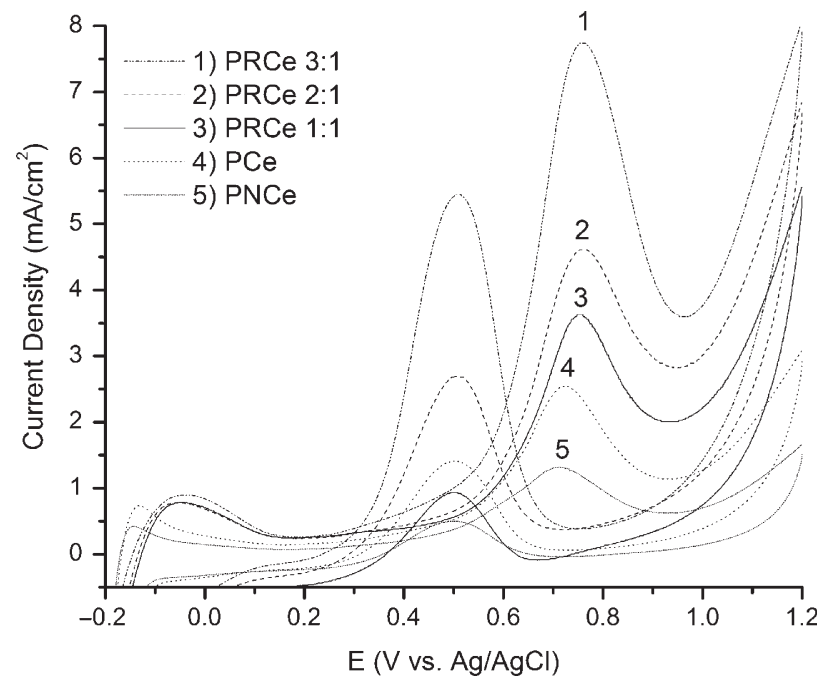

Fig. 8. Cyclic voltammetry of MWCNT composite electrodes towards the oxidation of $1 \mathrm{M}$ methanol in $0.5 \mathrm{M} \mathrm{H}_{2} \mathrm{SO}_{4}$ with correction for $\mathrm{Pt}$ surface area. The PRCe 3:1 electrode shows the highest catalytic ability towards methanol oxidation. 
provided by $\mathrm{Ru}$ is greater than the adverse effect of lowering the overall $\mathrm{Pt}$ surface concentration in the sample suggesting a synergistic catalytic effect between $\mathrm{Pt}, \mathrm{Ru}$ and ceria for methanol oxidation. The data also is supported by previous studies which demonstrate the addition of $\mathrm{Ru}$ in Pt composites can greatly enhance the oxidation of alcohols. ${ }^{(14-16)}$ Since $\mathrm{Pt}$ is the primary catalytic material for methanol oxidation, lowering Pt surface concentration by increasing secondary $\mathrm{Ru}$ catalyst concentration would eventually lead to a ratio of $\mathrm{Pt}: \mathrm{Ru}$ that shows lower overall catalytic ability. The PRCe 1:1 electrode displays lower catalytic ability than the other $\mathrm{Pt} / \mathrm{Ru}$ composite electrodes. The $j_{\mathrm{pa}}$ of PRCe 1:1 approaches similar values to that of the PCe electrode indicating that at certain concentrations the Ru acts to decrease the methanol oxidation ability of $\mathrm{Pt} / \mathrm{Ru}$ composite catalysts. This supports the argument that there is an optimal concentration of metal ions during synthesis which results in composite material with higher catalytic ability for methanol oxidation. As expected the PNCe electrode provides the lowest catalytic ability due to the absence of ceria and $\mathrm{Ru}$.

It is also notable to discuss the peak current density in the cathodic scan $\left(j_{\mathrm{pc}}\right)$. This large peak in the reverse scan is most often attributed to the stripping of $\mathrm{CO}$ and other carbacious species from the surface of electrodes during methanol oxidation. Such species form during the incomplete oxidation of methanol and the ratio of $j_{\mathrm{pa}} / j_{\mathrm{pc}}$ can indicate a preferential increase in catalytic ability versus formation unreacted byproducts. A lower $j_{\mathrm{pc}}$ may also indicate a preferential increase in the complete oxidation mechanism of methanol. All electrodes, regardless of ceria and $\mathrm{Ru}$ content, show relatively low $j_{\mathrm{pc}}$. Bulk Pt is known to produce a high $j_{\mathrm{pc}}$ due to the adsorption of $\mathrm{CO}$ while the addition of $\mathrm{Ru}$ and ceria are known to reduce this peak. The formation of well dispersed Pt nanoparticles can help explain why the PNCe electrode maintains a low $j_{\mathrm{pc}}$ while containing no ceria or Ru. The Pt nano-particle morphology and surface area may reduce the $\mathrm{CO}$ adsorption and also the cathodic oxidation peak. The MWCNT composite with the highest $j_{\mathrm{pa}} / j_{\mathrm{pc}}$ ratio is the MWCNT/Ceria Pt: Ru 1:1 (that ratio being 4.4). This indicates that, as suspected, the Ru and ceria content acts to limit the formation of $\mathrm{CO}$ and other byproducts of the incomplete oxidation of methanol. It is believed that the proximity of $\mathrm{Ru}$ and ceria nanoparticles to $\mathrm{Pt}$ nanoparticles supported on MWCNTs as indicated by TEM allows for the reaction of $\mathrm{CO}$ adsorbed species on $\mathrm{Pt}$ with $\mathrm{OH}$ adsorbed species on $\mathrm{Ru}$ and ceria.

\subsection{Electrooxidation of Ethanol}

In addition to methanol, the modified electrodes were also tested for electrochemical oxidation of ethanol. Ethanol's use as a fuel has been hailed promising, but its application in DAFCs has been limited due to the need to break the carbon-carbon $(\mathrm{C}-\mathrm{C})$ bond. Many composite catalysts have been proposed for ethanol oxidation in order to promote the direct oxidation mechanism, or increase the amount of AA produced in the incomplete mechanism. Similar to the methanol procedure, electrodes were exposed to $1 \mathrm{M}$ ethanol solutions in $0.5 \mathrm{M} \mathrm{H}_{2} \mathrm{SO}_{4}$ electrolyte and characterized using CV. Prior to $\mathrm{CV}$ all, ethanol solutions were bubbled with $\mathrm{N}_{2}$ for 15 minutes to remove all $\mathrm{O}_{2}$ dissolved in solution. The ordinate of the $\mathrm{CV}$ is presented in current density $\left(\mathrm{mA} / \mathrm{cm}^{2}\right)$ which was calculated from the Pt surface area. Results for ethanol oxidation were very similar to methanol oxidation and the overlaid CVs can be seen in Figure 9. It can clearly be seen that once the surface effect are normalized, all composite electrodes with $\mathrm{Ru}$ show significantly greater $j_{\mathrm{pa}}$ at $0.8 \mathrm{~V}$ versus $\mathrm{Ag} / \mathrm{AgCl}$ than electrodes without $\mathrm{Ru}$. This may indicate that $\mathrm{Ru}$ has a greater impact on ethanol oxidation than methanol oxidation. The oxidation of ethanol on Pt catalysts has been well documented to produce two peaks in the anodic scan at $\sim 0.8 \mathrm{~V}$ and $\sim 1.1 \mathrm{~V}$ versus $\mathrm{Ag} / \mathrm{AgCl}$ and these peaks are attributed to the complete and incomplete oxidation mechanisms of ethanol respectively. Figure 9 shows a clear trend for the peak at $0.8 \mathrm{~V}$ (complete oxidation). While the peak at $1.1 \mathrm{~V}$ remains relatively similar for electrodes containing $\mathrm{Ru}$, the peak at $0.8 \mathrm{~V}$ tends to increase as the concentration of $\mathrm{Pt}$ increases. This suggests that at certain concentrations of $\mathrm{Pt} / \mathrm{Ru}$, the reaction may proceed preferentially through the complete or incomplete oxidation mechanism. It seems in this study that higher Pt concentrations direct the mechanism toward the complete oxidation of ethanol. While higher Ru concentrations may prefer the incomplete oxidation, it is apparent that the overall kinetics of ethanol oxidation is greatly enhanced by the addition of Ru. Indeed,

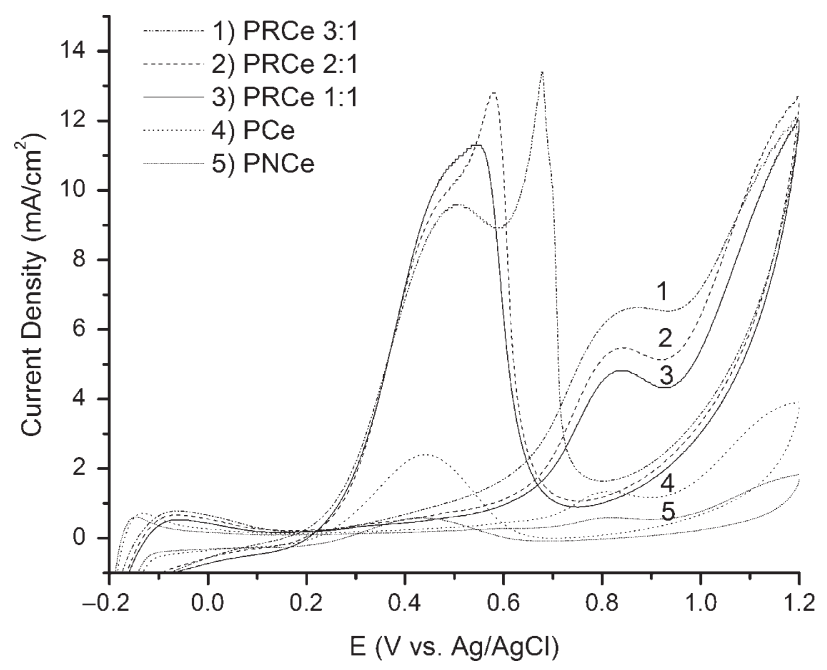

Fig. 9. Cyclic voltammetry of MWCNT composite electrodes towards the oxidation of $1 \mathrm{M}$ ethanol in $0.5 \mathrm{M} \mathrm{H}_{2} \mathrm{SO}_{4}$ with correction for $\mathrm{Pt}$ surface area. Similar to methanol, the PRCe 3:1 maintains the highest catalytic ability. 
the PRCe 3:1 electrode has a $j_{\mathrm{pa}}$ that is more than 20 times greater than that of the unmodified Pt electrode (Table II). The PRCe 2:1 and PRCe 1:1 electrodes also have much higher $j_{\mathrm{pa}}$ than the UP electrode (18.7 times greater and 16 times greater respectively). When $\mathrm{Ru}$ is not included in the composite, the $j_{\mathrm{pa}}$ drops significantly as demonstrated by the $j_{\mathrm{pa}}$ of the PNCe electrode which is only 1.7 times greater than that of the UP electrode. The inclusion of ceria also seems to greatly enhance the catalytic ability of ethanol oxidation. The PCe electrode shows 4.7 times higher $j_{\mathrm{pa}}$ than the UP electrode.

It is possible, through the incomplete oxidation mechanism, that $\mathrm{Ru}$ promotes the formation of acetic acid yielding $4 \mathrm{e}^{-}$per every ethanol as compared to $2 \mathrm{e}^{-}$during the formation of acetaldehyde or ethane-1,1-diol. The complex nature of ethanol oxidation leads to a variety of unreacted byproducts which lower the overall current expected during electrooxidation reactions. Further studies are needed to determine the exact role of $\mathrm{Ru}$ in the catalytic oxidation of ethanol. Similar to methanol, all the ceria containing electrodes promoted faster oxidation than electrodes without ceria. Ceria may, in addition to $\mathrm{CO}$ removal, promote the complete oxidation mechanism of ethanol leading to higher currents and less formation of unreacted carbacious species. The electrochemical results for methanol and ethanol oxidation are provided in Table II. The peak currents $\left(i_{\mathrm{pa}}\right)$ and peak current densities $\left(j_{\mathrm{pa}}\right)$ are reported for the oxidation of methanol and ethanol.

\section{CONCLUSIONS}

We have demonstrated a completely aqueous process for synthesizing novel PSS/MWCNT supported Pt/Ru/Ceria nanoparticles. These composites were characterized and used to fabricate composite electrodes for direct alcohol fuel cells. The electrochemical oxidation of methanol and ethanol was studied on all composite electrodes using cyclic voltammetry and compared to unmodified Pt electrodes. It is seen that a $\mathrm{Pt}: \mathrm{Ru}$ 5.8:1 ratio shows the best catalytic ability with roughly 20 times greater $j_{\mathrm{pa}}$ than the unmodified Pt electrode for both methanol and ethanol oxidation. When surface area effects were eliminated, electrodes made with $\mathrm{Ru}$ all showed faster oxidation kinetics than electrodes without Ru. Every electrode modified with ceria shows greater catalytic activity than electrodes without ceria. The effect of $\mathrm{Ru}$ and ceria on the completion oxidation of alcohols is currently under investigation through monitoring the composition of oxidation products. It is believed that the synthetic approaches in this study can be applied to the fabrication of composite electrodes with various transition metal/metal oxide composition including $\mathrm{Pt} / \mathrm{Au} / \mathrm{Ceria}, \mathrm{Pt} / \mathrm{Pd} / \mathrm{Ceria}$ and others. These results are promising for the development of novel direct alcohol fuel cells and warrant further research in order to identify and quantify the actual products from the oxidation of methanol and ethanol and correlate the electrochemical behavior with theoretical predictions.

Acknowledgments: The financial support from National Science Foundation (DMR 0746499) is gratefully acknowledged. The characterization of materials was performed at Material Characterization Facility at the University of Central Florida.

\section{References and Notes}

1. J. M. Anderson, A. Karakoti, D. J. Dáz, and S. Seal; Nanoceriamodified platinum-gold composite electrodes for the electrochemical oxidation of methanol and ethanol in acidic media; J. Phys. Chem. C 114, 4595 (2010).

2. J. M. Anderson, J. Patel, A. S. Karakoti, N. Greeneltch, D. J. Díaz, and S. Seal; Aging effects of nanoscale ceria in ceria-platinum composite electrodes for direct alcohol electro-oxidation; Electrochimica Acta 56, 2541 (2011).

3. G. Girishkumar, T. D. Hall, K. Vinodgopal, and P. V. Kamat; Single wall carbon nanotube supports for portable direct methanol fuel cells; J. Phys. Chem. B 110, 107 (2006).

4. S. S. Gupta and J. Datta; An investigation into the electro-oxidation of ethanol and 2-propanol for application in direct alcohol fuel cells (dafcs); J. Chem. Sci 117, 337 (2005).

5. Q.-Z. Lai, G.-P. Yin, Z.-B. Wang, C.-Y. Du, P.-J. Zuo, and X.-Q. Cheng; Influence ofmethanol crossover on the fuel utilization of passive direct methanol fuel cell; Fuel Cell 8, 399 (2008).

6. C. Lamy, A. Lima, V. LeRhun, F. Delime, C. Coutanceau, and J.-M. Leger; Recent advances in the development of direct alcohol fuel cells; J. Power Sources 105, 283 (2002).

7. H.-F. Wang and Z.-P. Liu; Selectivity of direct ethanol fuel cell dictated by a unique partial oxidation channel; J. Phys. Chem. C (2007).

8. S. S. Kumar and K. L. N. Phani; Exploration of unalloyed bimetallic $\mathrm{Au}-\mathrm{Pt} / \mathrm{C}$ nanoparticles for oxygen reduction reaction; J. Power Sources 187, 19 (2009).

9. M.-L. Lin, C.-C. Huang, M.-Y. Lo, and C.-Y Mou; Well-ordered mesoporous carbon thin film with perpendicular channels: Application to direct methanol fuel cell; J. Phys. Chem. C 112, 867 (2007).

10. J. Luo, M. M. Maye, V. Petkov, N. N. Kariuki, L. Wang, P. N. Njoki, D. Mott, Y. Lin, and C. J. Zhong; Phase properties of carbonsupported gold-platinum nanoparticles with different bimetallic compositions; Chem. Mater. 17, 3086 (2009).

11. K.-W. Park, J.-H. Choi, B.-K. Kwon, S.-A. Lee, Y.-E. Sung, H. Ha, S.-A. Hong, H. Kim, and A. Wieckowski; Chemical and electronic effects of $\mathrm{Ni} \mathrm{InPt} / \mathrm{Ni}$ and $\mathrm{Pt} / \mathrm{Ru} / \mathrm{Ni}$ alloy nanoparticles in methanol electrooxidation; J. Phys. Chem. B 106, 1869 (2009).

12. T. K. Sau, M. Lopez, and D. V. Goia; Method for preparing carbon supported Pt-Ru nanoparticles with controlled internal structure; Chem. Mater. (2009).

13. H. Schulenburg, E. Müller, G. Khelashvili, T. Roser, H. Bnnemann, A. Wokaun, and G. G. Scherer; Heat-treated ptco3 nanoparticles as oxygen reduction catalysts; J. Phys. Chem. C 113, 4069 (2009).

14. S. G. Lemos, R. T. S. Oliveira, M. C. Santos, P. A. P. Nascente, L. O. S. Bulhões, and E. C. Pereira; Electrocatalysis of methanol, ethanol and formic acid using a $\mathrm{Ru} / \mathrm{Pt}$ metallic bilayer; J. Power Sources 163, 695 (2007).

15. W. Li, X. Wang, Z. Chen, M. Waje, and Y. Yan; Pt-ru supported on double-walled carbon nanotubes as high-performance anode catalysts for direct methanol fuel cells; J. Phys. Chem. B 110, 15353 (2006).

16. M. Wakisaka, S. Mitsui, Y. Hirose, K. Kawashima, H. Uchida, and M. Watanabe; Electronic structures of Pt-Co and Pt-Ru alloys for Co-tolerant anode catalysts in polymer electrolyte fuel cells studied by EC-XPS; J. Phys. Chem. B 110, 23489 (2006). 
17. R. Alcalá, M. Mavrikakis, and J. A. Dumesic; Dft studies for cleavage of $\mathrm{C}-\mathrm{C}$ and $\mathrm{C}-\mathrm{O}$ bonds in surface species derived from ethanol onPt(111); J. Catal. 218, 178 (2003).

18. I. Kim, O. H. Han, S. A. Chae, Y. Paik, S.-H. Kwon, K.-S. Lee, Y.-E. Sung, and H. Kim; Catalytic reactions in direct ethanol fuel cells; Angew. Chem. Int. Ed. 50, 2270 (2011).

19. J. B. Park, J. Graciani, J. Evans, D. Stacchiola, S. D. Senanayake, L. Barrio, P. Liu, J. F. Sanz, J. Hrbek, and J. A. Rodriguez; Gold, copper, and platinum nanoparticles dispersed on $\mathrm{CeOx} / \mathrm{TiO}_{2}(110)$ surfaces: High water-gas shift activity and the nature of the mixedmetal oxide at the nanometer level; J. Am. Chem. Soc. 132, 356 (2009).

20. P. Heo, M. Nagao, M. Sano, and T. Hibino; A high-performance $\mathrm{Mo}_{2} \mathrm{C}-\mathrm{ZrO}_{2}$ anode catalyst for intermediate-temperature fuel cells; J. Electrochem. Soc. 154, B53 (2007).

21. M. Fernández-García, A. Martínez-Arias, L. N. Salamanca, J. M Coronado, J. A. Anderson, J. C. Conesa, and J. Soria; Influence of ceria on pd activity for the $\mathrm{CO}_{+} \mathrm{CO}_{2}$ reaction; J. Catal. 187, 474 (1999).

22. T. Raju and C. A. Basha; Electrochemical cell design and development for mediated electrochemical oxidation-Ce(iii)/Ce(iv)system; Biochem. Eng. J. 114, 55 (2005).

23. M. F. P. d. Silva, H. C. d. J. F. d. Costa, E. R. Triboni, M. r. J. Politi, and P. C. Isolani; Synthesis and characterization of $\mathrm{CeO}_{2}-$ graphene composite; J. Therm. Anal. Calorim. (2011).

24. M. Takahashi, T. Mori, A. Vinu, H. Kobayashi, J. Drennan, and D.-R. Ou; Preparation and anode property of $\mathrm{Pt}-\mathrm{CeO}_{2}$ electrodes supported on carbon black for direct methanol fuel cell applications; J. Mater. Res. 21, 2314 (2006).

25. A. Karakoti, S. V. N. T. Kuchibhatla, K. S. Babu, and S. Seal; Direct synthesis of nanoceria in aqueous polyhydroxyl solutions; $J$. Phys. Chem. C 111, 17232 (2007).

26. E. G. Heckert, S. Seal, and W. T. Self; Fenton-like reaction catalyzed by the rare earth inner transition metal cerium; Environ. Sci. Technol. 42, 5014 (2008)

27. D. J. Dáz, N. Greenletch, A. Solanki, A. Karakoti, and S. Seal Novel nanoscale ceria-platinum composite electrodes for direct alcohol electro-oxidation; Catal. Lett. 119, 319 (2007).

28. V. Singh, A. Karakoti, A. Kumar, A. Saha, S. Basu, and S. Seal; Precursor dependent microstructure evolution and nonstoichiometry in nanostructured cerium oxide coatings using the solution precursor plasma spray technique; J. Am. Ceram. Soc. 1 (2010).

29. S. V. N. T. Kuchibhatla, A. Karakoti, D. C. Sayle, H. Heinrich, and S. Seal; Symmetry-driven spontaneous self-assembly of nanoscale ceria building blocks to fractal superoctahedra; Cryst. Growth Des. 9, 1614 (2009)

30. G. Wu and B.-Q. Xu; Carbon nanotube supported Pt electrodes for methanol oxidation: A comparison between multi- and single-walled carbon nanotubes; J. Power Sources 174, 148 (2007).

31. B. Xue, P. Chen, Q. Hong, J. Lin, and K. L. Tan; Growth of Pd, $\mathrm{Pt}, \mathrm{Ag}$ and $\mathrm{Au}$ nanoparticles on carbon nanotubes; J. Mater. Chem. 11, 2378 (2001).

32. H. Yuan, D. Guo, X. Li, L. Yuan, W. Zhu, L. Chen, and X. Qiu; The effect of $\mathrm{CeO}_{2}$ on $\mathrm{Pt} / \mathrm{CeO}_{2} / \mathrm{CNT}$ catalyst for co electrooxidation; Fuel Cells 9, 121 (2009).

33. C. Wang, M. Waje, X. Wang, J. M. Tang, R. C. Haddon, and Y. Yan; Proton exchange membrane fuel cells with carbon nanotube based electrodes; Nano Lett. 4, 345 (2004)

34. S. Wang, S. P. Jiang, T. J. White, J. Guo, and X. Wang; Electrocatalytic activity and interconnectivity of Pt nanoparticles on multiwalled carbon nanotubes for fuel cells; J. Phys. Chem. C 113, 18935 (2009).

35. Y. Xing; Synthesis and electrochemical characterization of uniformly-dispersed high loading pt nanoparticles on sonochemically-treated carbon nanotubes; J. Phys. Chem. B 108, 19255 (2004)

36. Z. Sun, X. Wang, Z. Liu, H. Zhang, P. Yu, and L. Mao; Pt-ru/ceo2/ carbon nanotube nanocomposites: An efficient electrocatalyst for direct methanol fuel cells; Langmuir 26, 12383 (2010).

37. R. Chetty, W. Xia, S. Kundu, M. Bron, T. Reinecke, W. Schuhmann, and M. Muhler; Effect of reduction temperature on the preparation and characterization of Pt-Ru nanoparticles on multiwalled carbon nanotubes; Langmuir 25, 3853 (2009).

38. J. M. D. Rodríguez, J. Alberto, H. Melián, and J. P. Peña; Determination of the real surface area of pt electrodes by hydrogen adsorption using cyclic voltammetry; J. Chem. Educ. 77, 1195 (2000).

39. D. Chen, Q. Tao, L. W. Liao, S. X. Liu, Y. X. Chen, and S. Ye; Determining the active surface area for various platinum electrodes; Electrocatal 2, 207 (2011).

40. M. J. Watt-Smith, J. M. Friedrich, S. P. Rigby, T. R. Ralph, and F. C. Walsh; Determination of the electrochemically active surface area of pt/c pem fuel cell electrodes using different adsorbates; J. Phys. D: Appl. Phys. 41 (2008).

41. C. L. Green and A. Kucernak; Determination of the platinum and ruthenium surface areas in platinum-ruthenium alloy electrocatalysts by underpotential deposition of copper. I. Unsupported catalysts; J. Phys. Chem. B 106, 1036 (2002).

Received: 2 January 2013. Revised/Accepted: 12 February 2013. 